\title{
Transcription Key
}

$\begin{array}{ll}\text { text } & \text { utterance in English } \\ \text { text } & \begin{array}{l}\text { original utterance in language other than English and translation from original } \\ \text { utterance }\end{array} \\ \text { text } & \text { original utterance in third language (other than English) } \\ \text { "text" } & \text { quoted or read text } \\ \text { TEXT } & \text { word spoken with emphasis } \\ \text { [text] } & \text { clarifying text not spoken by informants } \\ \text { (inaudible) } & \text { utterance that cannot be clearly heard } \\ \text {... } & \text { longer pause } \\ \text { text - } & \text { utterance that is cut off }\end{array}$

